\title{
Would Rural Residents Will to Pay for Environmental Project? An Evidence in China
}

\author{
Xuyin Zhang, Ruimei Wang, Tianzhen Wu, Huan Song, Chuanfeng Liu \\ College of Economics and Management, China Agricultural University, Beijing, China \\ Email: tcherevan2001@aliyun.com
}

Received 13 April 2015; accepted 4 May 2015; published 5 May 2015

Copyright (C) 2015 by authors and Scientific Research Publishing Inc.

This work is licensed under the Creative Commons Attribution International License (CC BY).

http://creativecommons.org/licenses/by/4.0/

(c) (i)

Open Access

\begin{abstract}
This research estimated Chinese rural residents' willingness to pay for rural solid wastes recycling project. Dichotomous choice format contingent valuation method was employed to diverse rural residents' preference. 4795 Households had been interviewed for collecting primary data, and had been estimated respondents' will by logistic regression model. It indicated that the respondents would refuse to support solid wastes recycling project due to households' income restriction. The mean annual WTP of rural residents were 23.41 Chinese Yuan per household. In conclusion the rural solid wastes recycling project is acceptable and accessible for implementation in Chinese rural area.
\end{abstract}

Keywords

Solid Wastes Pollution, Willingness to Pay, Contingent Valuation Method, Rural China

\section{Introduction}

With the rapidly growth of economy in the past three decades, Chinese living standard has been extraordinarily improved. At the same time, environmental issues in rural area are increasingly deteriorated. Industrial wastes, the excessive using of fertilizers and pesticides are playing important roles in environmental pollution in rural area. Besides, discharging of solid wastes is also aggravating rural environment. In general, rural solid wastes are including: 1) Crop residues, for instance straws, weeds, leaves, cirrus and etc.; 2) Livestock and poultry residues; 3) Agricultural films; 4) Manipulate and domestic wastes [1].

Discharging of none pre-treated solid wastes in rural area would cause atmospheric, water and soil issues; furthermore it also endangers public benefits in diverse aspects. For instance, rural community environment would be defaced by solid wastes, which would reduce rural living qualities. Moreover, in term of pollution,

How to cite this paper: Zhang, X.Y., Wang, R.M., Wu, T.Z., Song, H. and Liu, C.F. (2015) Would Rural Residents Will to Pay for Environmental Project? An Evidence in China. Modern Economy, 6, 511-519.

http://dx.doi.org/10.4236/me.2015.65050 
solid wastes are damaging atmospheric, water and soil, which would be indirectly causing of health issues to residents. However, there still has no appropriate solution for dealing with solid wastes pollution despite of environment being observed damaged in rural China. Hence, environmental preservation is of significantly importance and urgency to rural china. Protection policies should be implemented to improve the living environments and guarantee the public health in rural area.

In this research, a contingent valuation method (CVM) was applied to estimate how much does rural residents would will to pay for ensuring a progressed living environment. Questions which trying to explain are: 1) Would rural residents will to pay for an improved environment? 2) What are the key factors impacting on residents' willingness to pay (WTP)? 3) How much are they going to pay? Based on these questions, questionnaire had been designed and investigated rural residents’ willingness-to-pay for pollution reduction.

\section{Literature Review}

Contingent valuation method (also known as CVM) is an effective method for evaluation of non-market assets such as environmental resources or public product. Study of CVM began with Ciriacy-Wantrup [2], after that Davis used the evaluation method in virtual market for empirical analysis of the value of entertainment, which opened the prelude to the practical application of the contingent valuation method [3]. In 1979, Bishop and Heberlein proposed to use dichotomous choice as the guidance technique of contingent valuation method [4]. In 1984, using the result of the questionnaire, Hanemann derived WTP function expression in an economic article [5]. After years of development, at the present dichotomous choice technique has been comprehensively applied as apriority choice to estimate mean of WTP.

Scholars have studied on the contingent valuation method and outcomes were fruitful. Thomas, Vukina, Ada, Wossink discussed the impact of environmental policies on agricultural land values in New Zealand [6], the conclusion is that price of land in environmental friendly policies areas is higher than that in the areas which did not implement environmental friendly policies. Spellerberg [7], Balmford, Bruner, Cooper [8] were using the contingent valuation method, estimated the value of biodiversity. Robert, Lorne estimated the value of the agricultural landscape's biological diversity in the Southern Ontario area [9]. Frank, Gregory and Eirivelthon evaluated the value of residential area's land where near the Brazil River [10].

In recent years, the numbers of using CVM to study the environmental issues has been increased. Tang Keyong used residents's willingness to accept compensation to calculate the environmental costs of Shanghai aquaculture ponds [11]. Yang Meng and Qian Xin used the Logit model with the income limit to discuss the recreation value of the reservoir [12]. Tang Xueyu, Zhang Haipeng and Li Shiping were using the Tobit model to calculate and discuss the willingness to pay of farmers on non-point source pollution control [13]. Using a valuation method, Jin Jianjun estimated the economic value of farmland protection policies [14].

To monetize the value of environmental assessment is one of the main directions of environmental resource management. The advantage of this method is that it can quantify the value of the processing resources and the environment, in order to reduce the difficulty in comparison of value between environmental resources and others that may have market value. It also has huge significance for developing of environmental policy, environmental impact assessment and other aspects of the economy.

\section{Materials and Methods}

\subsection{Questionnaire Design}

The questionnaire was consisting of 4 sections: 1) backgrounds introduction; 2) referendum questions; 3) socioeconomics questions; 4) psychological questions and pollution awareness questions. At the first section questionnaire provided the backgrounds information to explain current environmental issues in rural area and described to respondents the details of rural solid wastes recycling project which they would vote for. The second section is meant to explore respondents' attitude about willingness-to-pay for solid waste recycling project. In the third section, respondents were required to provide personal socioeconomics information, such as: gender, age level, years of study, and sources of income, how many children and elders in family, household income (Chinese Yuan), etc. In the last section, the respondents were required to give their views of attitude for solid waste discharging and environmental pollutions.

The questionnaire had applied closed-end questions to derive the respondents' preference: referendum choice questions were provided to ask respondents if they would accept to pay for the project or not, and subject to their 
answers, another adjusted bid value was given to them, for repeating twice until their final preference revealed. Therefore it would come up with 6 different answers: YYY, YYN, YN, NNN, NNY and NY, and the results would available at Table 1 below.

\subsection{Data Collection}

CVM has various methods to collect data, such as household interviews, mail questionnaires, telephone survey and E-mailed questionnaires. However, the internet infrastructure has serious deficiencies in Chinese rural areas. The internet questionnaires were inaccessible to the most of rural residents. Thus, in where employed household interviews to collect demographic, cognitive valuation, psychological data in this research.

Fortunately the numerous household data had been collected through questionnaires and had been approached in summer 2013, from April to August. The survey covered 30 provinces of China, including Hebei, Shandong, Henan, Anhui and etc. There were 157 questionnaires has been removed due to missing information, and 4638 completed questionnaires has been employed in this study and the descriptive statistics is available at Table 2 .

As an expectable result, the gender is consisting of male by $51.35 \%$ and the gender ratio of the survey data is 1.055 (male:female). Age level: In general, over $60 \%$ of respondents were 30 - 49 year old; about $18 \%$ of the respondents for 18 - 19 year old; about $18 \%$ of the total population were 50 to 59 years old and over 60 . Education level, $46 \%$ of respondents had basic education, $23 \%$ of respondents had secondary education and $30 \%$ of respondents had tertiary education. With respect to income, the households' average annual income was 14,000 $1600 \$$. Therefore, this survey can accurately reflect the real condition of rural residents. The survey revealed that $58 \%$ of respondents expressed their willingness-to-pay for pollution reduction while $24 \%$ declined, and $16 \%$ of respondents did not provide their attitudes.

\subsection{Methodology}

In this research, the contingent valuation method (CVM) has been employed to obtain respondents' will and applied Hanemann's method to evaluate respondents' mean WTP which were mentioned in Section 2, the respondents' answer for pollution reduction expressed as follow:

$$
y=a+b X+c T+r
$$

where $y$ is the respondents' choice from each alternative; $X$ indicates socioeconomic factors that would influence $y$; and $T$ is the bid value for WTP; $a, b, c$ are parameters and $r$ is error.

Consequently, the logistic regression had been applied to compute respondents' WTP due to characteristic of $y$.

$$
\eta=\log \frac{p}{1-p}=b_{0}+\sum_{i=1}^{n} b_{i} x_{i}
$$

where $\eta$ is concocting to the Bernoulli distribution and could link the liner function to the logistic or prohibit model. When respondents give a "no" answer, $y$ would have a negative value. Thus: $r \leq-a-b X-c T$. Assume that $F$ is a function of $r$, the probability of "no" is $P_{\text {по }}(x)=F(-a-b X-c T)$, and the probability of "yes" is $P_{\text {yes }}=1-F(-a-b X-c T)$. Based on Hanemann's logistic model, the probability of "yes" can be written as:

$$
P_{\text {yes }}=1-\frac{1}{1+\mathrm{e}^{(a+b X+c T)}}
$$

\begin{tabular}{|c|c|c|c|c|c|}
\hline \multicolumn{2}{|c|}{ YYY } & \multicolumn{2}{|c|}{ YYN } & \multicolumn{2}{|c|}{ YN } \\
\hline Frequency & $\%$ & Frequency & $\%$ & Frequency & $\%$ \\
\hline 1427 & 0.500526131 & 359 & 0.12592073 & 584 & 0.20484 \\
\hline \multicolumn{2}{|c|}{ NNN } & \multicolumn{2}{|c|}{ NNY } & \multicolumn{2}{|c|}{ NY } \\
\hline Frequency & $\%$ & Frequency & $\%$ & Frequency & $\%$ \\
\hline 179 & 0.062784988 & 169 & 0.059277447 & 133 & 0.04665 \\
\hline
\end{tabular}

Table 1. Respondents' preferences. 
Table 2. Descriptive statistics.

\begin{tabular}{|c|c|c|c|}
\hline \multicolumn{2}{|c|}{ Variable } & \multirow{2}{*}{$\begin{array}{c}\text { Frequency } \\
2462\end{array}$} & \multirow{2}{*}{$\begin{array}{c}\% \\
0.5135\end{array}$} \\
\hline \multirow{2}{*}{ Gender } & Male & & \\
\hline & female & 2333 & 0.4865 \\
\hline \multirow{5}{*}{ Age level } & $18-29$ & 867 & 0.1808 \\
\hline & $30-39$ & 1298 & 0.2707 \\
\hline & $40-49$ & 1738 & 0.3625 \\
\hline & $50-59$ & 600 & 0.1251 \\
\hline & Over 60 & 292 & 0.0609 \\
\hline \multirow{5}{*}{ Years of study } & 9 and less & 2219 & 0.4628 \\
\hline & $10-12$ & 1125 & 0.2346 \\
\hline & $13-15$ & 372 & 0.0776 \\
\hline & $16-17$ & 910 & 0.1898 \\
\hline & Over 18 & 169 & 0.0352 \\
\hline \multirow{7}{*}{ Sources of income } & Farm & 2155 & 0.4494 \\
\hline & Farm and sideline & 562 & 0.1172 \\
\hline & Migration working & 1371 & 0.2859 \\
\hline & Self-employment & 700 & 0.146 \\
\hline & Livestock and aquaculture & 240 & 0.0501 \\
\hline & Public employee & 464 & 0.0968 \\
\hline & etc. & 651 & 0.1358 \\
\hline \multirow{2}{*}{ Elder in family } & Yes & 3494 & 0.7287 \\
\hline & No & 1301 & 0.2713 \\
\hline \multirow{2}{*}{ Child in family } & Yes & 3724 & 0.7766 \\
\hline & No & 1071 & 0.2234 \\
\hline \multirow{11}{*}{ Household Income (Chinese Yuan) } & 4000 and less & 518 & 0.108 \\
\hline & {$[4000-6000)$} & 438 & 0.0913 \\
\hline & {$[6000-8000)$} & 358 & 0.0747 \\
\hline & {$[8000-10,000)$} & 422 & 0.088 \\
\hline & {$[10,000-12,000)$} & 394 & 0.0822 \\
\hline & {$[12,000-14,000)$} & 207 & 0.0432 \\
\hline & {$[14,000-16,000)$} & 352 & 0.0734 \\
\hline & {$[16,000-20,000)$} & 396 & 0.0826 \\
\hline & {$[20,000-25,000)$} & 303 & 0.0632 \\
\hline & {$[25,000-30,000)$} & 258 & 0.0538 \\
\hline & Over 30000 & 1149 & 0.2396 \\
\hline \multirow{3}{*}{ Willingness to Pay } & Yes & 2851 & 0.5946 \\
\hline & No & 1162 & 0.2423 \\
\hline & Not Sure & 782 & 0.1631 \\
\hline
\end{tabular}


As the expected probabilities of "yes" and "no" are the same, thus if $T>0$, the expected WTP is:

$$
E(\mathrm{WTP})=\int_{0}^{T \max }(1-F(-a-b X-c T)) \mathrm{d} x=\int_{0}^{T \max } 1-\frac{\mathrm{d} x}{1+\mathrm{e}^{a+b X+c T}}
$$

Thus, the mean WTP would be written as:

$$
E(\text { WTP })=\frac{1}{C} \ln \frac{1+\mathrm{e}^{a+\sum b_{i} x_{i}+c T \max }}{1+\mathrm{e}^{a+\sum b_{i} x_{i}}}
$$

\section{Results and Analysis}

\subsection{Descriptive Analysis}

Whether the rural household leaders financially support the project is presented in Table 3. It is revealed that over $92 \%$ of respondents believe that the solid wastes recycling project should be implemented in China rural area, nevertheless, only $59.46 \%$ of respondents would agree to be charged by approaching the project. In another side, it is up to $40.54 \%$ (1944 individuals) respondents refused to support the project financially. Thus it implied that the rural solid wastes recycling project is acceptable to most of rural residents in conception. Nonetheless, it is unacceptable in finance. That is a truly dilemma for implementing the rural solid waste recycling project in Chinese rural area. The percentage of population who were willing to pay for the project is not as much as its demands. In general, there are two reasons might be intercepting to explain this phenomenon: 1) China rural residents have not form concepts of environmental protection as a developing country. They are used to having the lifestyle as natural economics era with outmoded customs; 2) Basis of the externality theory, the environment could be considered as a sort of element which is involved with external benefits or costs. Consequently, rational individuals would prefer to optimize their utilities to achieve maximum conditions. Therefore, as a rational rural resident, they would ordinarily deposit solid wastes with methods which would meet their maximum utilities, for instance, exposing wastes in remote places without pre-treatment. Both of reasons would cause the phenomenal above. Therefore, to discover factors that impact on rural residents' preferences is the initialized path to understand why and how rural residents would reject or accept to financially support the rural solid wastes recycling project.

Table 4 presented the respondents' reasons that rejected to financially support the project. There are $23 \%$ residents refusing financial support due to the project is doubtable to achieve its aim. With respect to household

Table 3. Rural residents' willing for the project.

\begin{tabular}{cccccc}
\hline \multicolumn{1}{c}{ Variable } & & $\%$ & Variable & $\%$ \\
\hline & Yes & 0.5946 & & Yes & 0.9235 \\
Would finically support the project? & No & 0.2423 & Does the project should be launched? & No & 0.0765 \\
\hline
\end{tabular}

\begin{tabular}{|c|c|}
\hline Reason & $\%$ \\
\hline Government would not use the money for the project & $17 \%$ \\
\hline Satisfied with current condition & $5 \%$ \\
\hline The project could not achieve its aim & $23 \%$ \\
\hline The project is not qualified to the personal aim & $7 \%$ \\
\hline Prefer other methods to support rather than financial methods & $17 \%$ \\
\hline Unable to afford the cost & $17 \%$ \\
\hline It should be done by government & $8 \%$ \\
\hline Etc. & $6 \%$ \\
\hline
\end{tabular}

Table 4. Reasons of refusing financial support. 
income restriction, over $17 \%$ respondents were not afford the project fees as an extra costs, while $17 \%$ of respondents would prefer other methods to support the project, for instance to be a volunteer and etc. Moreover, about $17 \%$ of respondents believed that the government would use charging fees in another purpose instead of using it for the project, while about $7 \%$ of respondents refused to support because of the project would not achieve their personal aims. In addition, there were $8 \%$ of respondents consider the environmental protection should be done by government not by rural residents, and $5 \%$ of respondents satisfied by current condition and consider the project is unnecessary.

\subsection{Estimate the Rejected Respondents}

The logistics model had been employed in this study to estimate the influences of respondents who rejected to financially support the project.

(1) Socioeconomics variables: based on the results in Table 5, the gender and income level were only two socioeconomics variables which were statistically significant. As the result, male would have more $20.6 \%$ probabilities to reject supporting the project than female. Moreover, the rejecting probabilities would be decreased by $7 \%$ while the increasing of household income level by 1 . As the estimation that the top income households would be $48 \%$ probabilities to reject supporting project in finance than the lowest income households in this study. Furthermore, the rest of socioeconomics variables were not statistically significant.

(2) Psychological variables: subject to the regression's results in Table 5, 3 attitude variables would be significant interpretation. Respondents frequently considered possible methods to solve rural solid wastes pollution would have lower probabilities to reject by $11 \%$. The rejection ratio of frequently considered respondents is $62 \%$ to the infrequently considered respondents. Thus in term of maximized individuals' utilities, the more residents concerned the environment around them, the smaller probabilities they would reject to support the project in finance. By contrast, to residents, who believe discharging solid waste in rural China is necessarily to their lifestyle, have higher probabilities to reject supporting the project by $46 \%$. Moreover, once a respondent considered that the rural area solid wastes would no need to be controlled, the probabilities to reject would raised up to $10 \%$. Therefore, they would have no demands for environmental protection and they were used to discharging solid wastes as a part of lifestyle. There was no doubting that those respondents rejected to support the project.

Furthermore, residents who believe their discharging behaviors were infected by their neighbors would have lower probabilities to reject supporting the project by 34\%. Employing the externality theory would thoroughly explain their choice. As a developing country, most of the rural areas in China are suffering in uncompleted infrastruction and inefficient public service system despite to the fact that China has achieved economic success in the past three decades. Rural residents discharge solid wastes in rough methods for purposes of reducing their time, labor, and economic costs. In addition, with a restricted income level, they had no motivations to consider environment as a priority than other sectors. In consequences, as long as they realized that their neighbors discharging wastes in a rough way, they would act in the exactly same way for psychological equilibrium.

Moreover, the rejection ratio would be reduced by 37\% if residents were aware of lacking, in techniques and related resources, which would cause solid wastes discharging. Thus those respondents had motivation to financially support the project for improved living environment.

(3) Pollution awareness variables: according to the result of rejection model, the pollution awareness variables were not significantly influencing respondents' choices. The possible explanation is that, on Table 2, up to $46 \%$ of respondents were not well educated (9 years or less in school), while they were in short of knowledge to understand the dangers of solid wastes pollution. In addition, only half of the respondents would distinguish the natural hazardousness of solid wastes pollution. And $60 \%$ of them in total could understand solid wastes pollution may cause psychical harms. In average, most of the rural residents were unnoticed about discharging solid wastes.

\subsection{Estimating Mean Willingness-To-Pay}

With respect to the Table 6, it was employing the STATA to estimate the logistic regressions of two models (WTP $>0$ and WTP $\geq 0$ ).

Based on the results, the mean WTP would be computed with following equation:

$$
E(\mathrm{WTP})=\frac{1}{c} \ln \frac{1+\mathrm{e}^{a+\sum b_{i} x_{i}+c T \text { max }}}{1+\mathrm{e}^{a+\sum b_{i} x_{i}}}
$$


Table 5. Rejecting respondents model.

\begin{tabular}{ccc}
\hline & Odds ratio & Coefficient \\
\hline a2 & 0.8903703 & $-0.1161178^{* * *}$ \\
a5 & 1.103732 & $0.0986968^{* * *}$ \\
a7 & 1.100092 & $0.0953937^{* * *}$ \\
a10 & 0.9351623 & $-0.0670351^{*}$ \\
a17 & 0.8918178 & $-0.1144935^{* * *}$ \\
Gender & 1.20627 & $0.187533^{* * *}$ \\
Income level & 0.9364784 & $-0.0656288^{* * *}$ \\
Constant & - & $-0.5992392^{* * * *}$ \\
\hline
\end{tabular}

Table 6. Binary logistics estimation.

\begin{tabular}{|c|c|c|c|c|}
\hline \multirow[b]{2}{*}{ Variables } & \multicolumn{2}{|c|}{ Estimating WTP $>0$} & \multicolumn{2}{|c|}{ Estimating WTP $\geq 0$} \\
\hline & Coefficient & Standard error & Coefficient & Standard error \\
\hline Bid & $0.0635873^{* * *}$ & 0.0040687 & $0.0520548^{* * *}$ & 0.0053945 \\
\hline Gender & $-0.1028469^{*}$ & 0.063757 & -0.0035554 & 0.0841399 \\
\hline Agelv & -0.0389375 & 0.0322158 & $-0.1147661^{* * *}$ & 0.0415124 \\
\hline Edulv & 0.0064152 & 0.0286522 & 0.0213839 & 0.0375437 \\
\hline Fsize & -0.0221529 & 0.0189565 & -0.0273409 & 0.0264607 \\
\hline Old & -0.099432 & 0.0740973 & -0.0475708 & 0.0971407 \\
\hline Child & -0.0610121 & 0.0802411 & -0.0285448 & 0.1054427 \\
\hline Incomelv & $0.0152207^{*}$ & 0.0089258 & $-0.0269118^{* *}$ & 0.0118937 \\
\hline a2 & $0.1791745^{* * *}$ & 0.0319282 & $0.2146222^{* * *}$ & 0.042329 \\
\hline a3 & -0.0339443 & 0.0290119 & -0.0472969 & 0.0386938 \\
\hline a5 & $-0.1798625^{* * *}$ & 0.0313472 & $-0.1986536^{* * *}$ & 0.0405392 \\
\hline a7 & $-0.064449^{*}$ & 0.034341 & -0.0242821 & 0.0455738 \\
\hline a8 & $0.0877017^{*}$ & 0.0458295 & $0.1245392^{* *}$ & 0.060782 \\
\hline a9 & 0.0409138 & 0.047809 & 0.0185092 & 0.0632519 \\
\hline a10 & -0.0185999 & 0.0432147 & -0.0524947 & 0.0570721 \\
\hline a11 & -0.0435198 & 0.035008 & -0.0118441 & 0.0460591 \\
\hline a15 & -0.0018867 & 0.0311818 & -0.0365139 & 0.0416763 \\
\hline a17 & $0.081767^{* *}$ & 0.0366018 & 0.0555955 & 0.0487531 \\
\hline a18 & 0.0373207 & 0.0481915 & 0.0651696 & 0.0624694 \\
\hline a19 & 0.0349846 & 0.0433692 & 0.0038634 & 0.0573961 \\
\hline v81 & 0.0538262 & 0.0396078 & 0.0734397 & 0.0529416 \\
\hline v82 & -0.0537821 & 0.0755971 & -0.0053753 & 0.0999776 \\
\hline v90 & $0.4542878^{* * *}$ & 0.119893 & $0.5824295^{* * *}$ & 0.1443776 \\
\hline (Constant) & $-1.2584^{* * *}$ & 0.2545964 & -.2062217 & 0.3305791 \\
\hline Willing-to-pay & \multicolumn{2}{|c|}{18.42617} & \multicolumn{2}{|c|}{23.41487} \\
\hline
\end{tabular}


where WTP > 0 was indicating that residents had strictly positive willing to support project, WTP $\geq 0$ was indicating that respondents had nonnegative willing to support project. The mean WTP of respondents who had strictly positive willing were 18.42 Chinese Yuan per household per year, and the mean WIP of respondents who had nonnegative willing were 23.41 Chinese Yuan per household per year.

In this research the sample were randomly selected through all reigns in Chinese rural area. Thus the sample would be able to represent the Chinese rural households. Respecting to the China statistic year book 2013 [15], the amount of households was 266.0697 million in rural china. Therefore, Chinese rural households would be willing to pay for solid wastes recycling project for 4.9023 billion and 6.23 billion Chinese Yuan per year.

\section{Conclusions}

The initial objective of this research was to evaluate rural residents' economic valuations for solid wastes recycling project. The important ingredients in this research were to understand whether rural residents were willing to pay for the project. It will be helpful to politician when making rural environmental public policies. Out of 4795 households, $59.46 \%$ were willing to pay, otherwise the rest would decline. In general, rural residents mean WTP is annual 23.41 Chinese Yuan per household. However, they would reject to pay for project due to reasons, for example, income restriction, distrust to government, diverse expectation to the project and etc. moreover, in this research also estimated preference influencing of socioeconomics, psychology and pollution awareness which were may cause rural residents to accept or reject supporting project in finance.

The Contingent Valuation Method is necessarily helpful for rural environment preservation. The results would be concerned in further studies for making public policies.

\section{Acknowledgements}

This paper was partially supported by National Key Technology R \& D Program of the Ministry of Science and Technology (No. 2014BAL07B05), Humanities and Social Sciences Foundation of Ministry of Education of China (No. 13YJCZH182) and Advance Research of China Agricultural University. Beijing, China (No. 2014RW021).

\section{References}

[1] Yang, Y. and Chen, J.S. (2003) Analysis and Prevention of farmland Pollution. Journal of Hefei University of Technology (Social Sciences), 17.

[2] Ciriacy-Wantrup, S.V. (1947) Capital Returns from Soil-Conservation Practices. Journal of Farm Economics, 29, 1181-1196. http://dx.doi.org/10.2307/1232747

[3] Davis, R.K. (1963) Recreation Planning as an Economic Problem. Natural Resources Journal, 3, $239-249$.

[4] Bishop, R.C. and Herberlein, T.A. (1979) Measuring Values of Extra Market Goods: Are Indirect Measure Biased. American Journal of Agricultural Economics, 61, 926-930. http://dx.doi.org/10.2307/3180348

[5] Hanemann, W.M. (1984) Welfare Evaluations in Contingent Valuation Experiments with Discrete Responses. American Journal of Agricultural Economics, 66, 332-341. http://dx.doi.org/10.2307/1240800

[6] Thomas, V. and Ada, W. (2000) Environmental Policies and Agricultural Land Values: Evidence from the Dutch Nutrient Quota System. Land Economics, 76, 413-429. http://dx.doi.org/10.2307/3147038

[7] Spellerberg, I.F. (1992) Evaluation and Assessment for Conservation: Ecological Guidelines for Determining Priorities for Nature Conservation. Chapman \& Hall, London. http://dx.doi.org/10.1007/978-94-011-2302-0

[8] Balmford, A., Bruner, A. and Cooper, P. (2002) Ecology-Economic Reasons for Conserving Wild Nature. Science, 297, 950-953.

[9] Robert, J.M. and Bennett, L.P. (2007) Biodiversity and Ecological Value of Conservation Lands in Agricultural landscapes of Southern Ontario, Canada. Landscape Ecology, 22, 657-670. http://dx.doi.org/10.1007/s10980-006-9063-5

[10] Merry, F., Amacher, G. and Lima, E. (2008) Land Values in Frontier Settlements of the Brazilian Amazon. World Development, 36, 2390-2401.

[11] Tang, K.Y., Yang, Z.Y., Yang, H.Y. and Fan, X.Y. (2012) Environmental Cost of Pond Aquiculture in Shanghai: An Empirical Analysis Based on Double-Bounded Dichotomous CVM Method. Acta Ecologica Sinica, 32, 2212-2222.

[12] Yang, M. and Qian, X. (2011) Environmental Valuation in Aging Dam Decision Making: A Case Study of Reservoir 
Recreation. China Environmental Science, 31, 1563-1570.

[13] Tang, X.Y., Zhang, H.P. and Li, S.P. (2012) Economic Value of Agricultural Non-Point Source Pollution Control. Chinese Rural Economy.

[14] Jin, J.J. and Jiang, C. (2011) Choice Experiment Method and Its Application to Cultivated Land Protection-A Case Study in Wenling City of Zhejiang Province. Journal of Natural Resources, 26, 1750-1757.

[15] National Bureau of Statistics of China (2014) China Statistical Yearbook 2013. China Statistics Press, Beijing. http://www.stats.gov.cn/tjsj/ndsj/2013/indexee.htm 